\title{
HAVE REINTUBATION IN INTENSIVE CARE UNIT MORE TECHNICAL DIFFICULTY AND COMPLICATIONS IN COMPARISON WITH FIRST INTUBATION? A PROSPECTIVE, OBSERVATIONAL STUDY
}

Adrián Martínez, Manuel Taboada, Aurora Baluja, Mónica Lombardía, Pablo Otero, Julián Álvarez Complejo Hospitalario Universitario de Santiago de Compostela. Dept of Anesthesiology and Intesive Care. Spain

\section{BACKGROUND}

Endotracheal intubation is a common intervention in Intensive Care Unit (ICU) associated with a high incidence of difficult intubation and complications. We hypothesized that reintubations in ICU would be associated with more technical difficulty and complications compared with first intubation.

\section{METHODS}

We prospectively evaluated during 34 months all patients that were intubated using a direct laryngoscopy and posteriorly reintubated in the ICU. The purpose of this study was to compare first time success rate, technical difficulty of intubation and the incidence of complications during intubation.

\begin{tabular}{|c|c|c|c|}
\hline & $\begin{array}{l}\text { First intubation } \\
\qquad(\mathrm{n}=48)\end{array}$ & $\begin{array}{l}\text { Reintubation } \\
\quad(n=48)\end{array}$ & $\mathrm{P}$ value \\
\hline \multicolumn{4}{|l|}{ Intubation attempts } \\
\hline 1 & $44(91,7)$ & $42(87,5)$ & ns \\
\hline 2 & $4(8,3)$ & $5(10,4)$ & ns \\
\hline$\geq 3$ & & $1(2)$ & ns \\
\hline Adjunct to DL used (gum-elastic bougie) & $3(6,25)$ & $9(18,7)$ & $<0,05$ \\
\hline Modified Cormack-Lehane grade glottic view & & & $<0,05$ \\
\hline 1 Full view of the glottis & $24(50)$ & $20(41,6)$ & \\
\hline 2a Partial view of the glottis & $12(25)$ & $5(10,4)$ & \\
\hline $2 \mathrm{~b}$ Arytenoid or posterior part of the vocal cords only just visible & $12(25)$ & $16(33)$ & \\
\hline 3 Only epiglottis visible & & $7(14,6)$ & \\
\hline $4 \quad$ Neither glottis nor epiglottis visible & & & \\
\hline Procedural complications & $12(25)$ & $20(41,6)$ & $<0,05$ \\
\hline Hypotension $<80 \mathrm{mmHg}$ & $11(22,9)$ & $16(33)$ & \\
\hline Hypotension $<65 \mathrm{mmHg}$ & $5(10,4)$ & $10(20,8)$ & \\
\hline Hypoxia $<90 \%$ & $5(10,4)$ & $10(20,8)$ & \\
\hline Hypoxia $<80 \%$ & $2(4,1)$ & $7(14,6)$ & \\
\hline Esophageal intubation & & $1(2)$ & \\
\hline
\end{tabular}

\section{RESULTS AND DISCUSSION}

A total of 340 patients were intubated in ICU, of which 48 (14\%) were reintubated posteriorly. No difference in the number of attempts of intubation were observed between the first intubation and the reintubation. Reintubation was associated with worse glottic visualization, with more use of gum-elastic bougie, and more complications compared with first intubation. Elmer et al. in a similar study observed more complications during reintubation compared to first intubation in their study.

\section{CONCLUSIONS}

Compared with first intubation in ICU, reintubation using a direct laryngoscopy was associated with worse glottic views, an increase of the technical difficulty of intubation and the incidence of complications. Further studies are required to confirm these findings.

\section{REFERENCES}

Elmer et al. Reintubation in critically ill patients: procedural complications and implications for care. Critical Care 2015; 19.112-18. 